\title{
Assessment of Cranial Sonographic Findings of Hypoxic Ischemic Brain Injury in Perinatal Asphyxia
}

TARANA YASMIN, ${ }^{1}$ SHAHEEN AKTHER, ${ }^{2}$ SOHELY SULTANA, ${ }^{3}$ MASHAH BINTE AMIN ${ }^{4}$

\begin{abstract}
:
Background: In perinatal asphyxia, hypoxic ischemic brain injury remains most serious condition causing significant mortality and long term morbidity. Early detection of intracranial changes and its consequences will enhance timely intervention and better out come. Cranial sonography can be done to assess the abnormalities of brain in perinatal asphyxia.

Objectives: The objective of this study was to evaluate usefulness of cranial sonography in perinatal asphyxia.

Methods: This was an observational study conducted from March 2014 to February 2015 at department of radiology and imaging, Enam Medical College and Hospital.Total 100 neonates with perinatal asphyxia were included in this study. Cranial USG was done in all cases and sonographic abnormalities were evaluated.

Result: 56 term ( $>37$ weeks of gestation ) and 44preterm ( $<37$ weeks of gestation ) newborn having birth asphyxia were taken as cases in this study. Common cranial sonographic findings of preterm babies were periventricular leukomalacia 29\% (I3), germinal matrix hemorrhage I4\% (6), Intraventricular hemorrhage II\% (5) cerebral oedema 7\% (3) and normal 39\% (I7). Common cranial USG findings in term babies were cerebral oedema 43\% (24), intracerebral hemorrhage 5\% (3), Focal cerebral infarct 4\% (2), Intraventricular hemorrhage $2 \%$ (I) and normal $46 \%$ (26).

Conclusion: This study found that transcranial sonography is useful to identify the abnormalities in brain of asphyxiated neonate and helps to predict the neurodevelopmental outcome. So proper management plan can be done.
\end{abstract}

Key words: Cranial sonography, perinatal, asphyxia.

\section{Introduction:}

Perinatal asphyxia is a condition characterized by an impairment of exchange of the respiratory gases (oxygen and carbon dioxide) resulting in hypoxemia and hypercapnia, accompanied by metabolic acidosis. Perinatal asphyxia represents the third most common cause of neonatal death. Neonatal mortality contributes a great deal to infant mortality rate. ${ }^{1,2}$ Among all the causes, $39 \%$ of the neonatal deaths occur due to perinatal asphyxia. ${ }^{3}$ Perinatal asphyxia may affect virtually any organ, but hypoxic-ischemic brain injury is the most studied clinical condition and that is burdened with the most severe sequelae. Hypoxic ischemic brain injury is the most important consequences of perinatal asphyxia which

1. Assistant Professor, Radiology dept. EMCH.

2. Professor and Head, Pediatric dept. EMCH

3. FCPS student Radiology dept. BSMMU.

4. Assistant Professor, Radiology dept. EMCH

Corresponding author: Dr. Tarana Yasmin, MBBS, FCPS, Assistant Professor, Department of Radiology and Imaging, Enam Medical College and Hospital, 9/3 Parbati Nagar, Thana Road, Savar, Dhaka. Mobile: 01715090961,Email: tarana_hassan@ hotmail.com. ultimately results in immediate and delayed form of neuronal death. ${ }^{4}$ So it is important to assess the severity of asphyxia to give adequate treatments and prevent brain damage. Cerebral sonography in neonatal period can assess the abnormality of brain caused by asphyxia and provide early guide to the neurodevelopmental prognosis.

Cranial ultrasound was first introduced in 1979 in neonatal care units to detect intracranial pathology. ${ }^{5,6}$ The development of high resolution, real time sector together with increasing expertise in its use and interpretation of finding, has established the role of sonography in the analysis of neonatal brain. Cranial ultrasound has become an essential diagnostic tool in modern neonatology for depicting normal anatomy and pathological changes in neonatal brain.

Because in the neonate many sutures and fontanels are still open and these can be used as acoustic window to look into the brain. ${ }^{7}$ It is also cost effective, radiation free and its safety is well established in infants. ${ }^{8}$ Now a day cranial ultrasound has been used routinely for infants at risk of neurological impairment such as who have suffered from birth asphyxia. This study was conducted to assess the cranial sonographic findings in neonates with perinatal asphyxia. 


\section{Materials and methods:}

This study was carried out in the department of radiology and imaging, ENAM Medical College and Hospital from March 2014 to February 2015. One hundred asphyxiated neonates were selected for the study and were subjected to cranial sonography.

After obtaining the informed consent from the mother or attendant proper maternal, perinatal, antenatal and obstetric history were collected. Detailed clinical examination was done. Age, sex, birth weight, gestational age, other parameters, complications, clinical diagnosis of the baby were recorded. Examination findings were documented on a pre formed questionnaire. Cranial ultrasound scans were performed with real time B mode gray scale machine with 3.5 MHz and 7.5 MHz transducer in department of Radiology and Imaging in EMCH. Anterior fontanele was used as acoustic window and scanning was done in both coronal and sagittal planes. Sonographic findings of ventricular size, haemorrhage within the ventricles and parenchyma, other parenchymal abnormalities, cerebral oedema were evaluated. Descriptive statistical analysis of all information and data was carried out.

\section{Results:}

One hundred newborn were enrolled in this study. Among them 44 babies were preterm and 56 babies were term with perinatal asphyxia. Mode of delivery was normal vaginal delivery for $46 \%$ neonates and $54 \%$ via LUCS for various reasons. There were $52 \%$ female and $48 \%$ were male neonates (Table I).

\section{Table-I}

Distribution of newborns according to gender $(n=100)$

\begin{tabular}{lcc}
\hline Gender & No of respondents & Percentage \\
\hline Male & 48 & $48 \%$ \\
Female & 52 & $52 \%$ \\
\hline
\end{tabular}

Out of one hundred babies highest number 82 (82\%) were in age group of 1 to 4 days.(Table II)

Table-II

Distribution of newborns according to age $(n=100)$

\begin{tabular}{lcc}
\hline Age & No of respondents & Percentage \\
\hline$<1$ day & 6 & $6 \%$ \\
$1-4$ days & 82 & $82 \%$ \\
$5-8$ days & 12 & $12 \%$ \\
\hline
\end{tabular}

Among the preterm babies, highest number 26 (59\%) were in the age group of 34-36 weeks of gestational age and among the term babies, highest number $38(68 \%)$ were in the age group of 37-39 weeks of gestational age (Table III \& IV).

Table-III

Distribution of preterm newborn as per gestational age $(n=44)$

\begin{tabular}{lcc}
\hline Gestational Age in weeks & $\begin{array}{c}\text { No of the } \\
\text { respondents }\end{array}$ & Percentage \\
\hline $31-33$ & 18 & $41 \%$ \\
$34-36$ & 26 & $59 \%$ \\
\hline
\end{tabular}

Table-IV

Distribution of term newborn as per gestational age $(n=56)$

\begin{tabular}{lcc}
\hline $\begin{array}{l}\text { Gestational Age } \\
\text { in weeks }\end{array}$ & $\begin{array}{c}\text { No of the } \\
\text { respondents }\end{array}$ & Percentage \\
\hline $37-39$ & 38 & $68 \%$ \\
$40-42$ & 18 & $32 \%$ \\
\hline
\end{tabular}

Table V \&VI shows that in preterm babies birth weight between $1.5-2 \mathrm{~kg}$ was in $14(32 \%)$ cases and between $>2$ $2.5 \mathrm{~kg}$ was in $30(68 \%)$ cases. In term babies, birth weight between $2.5-3.5 \mathrm{~kg}$ was in $40(71 \%)$ cases and between $>3.5$ $4 \mathrm{~kg}$ was in $16(29 \%)$ cases.

Table-V

Distribution of preterm neonates as per birth weight $(n=44)$

\begin{tabular}{lcc}
\hline Birth weight & $\begin{array}{c}\text { No. of the } \\
\text { respondents }\end{array}$ & Percentage \\
\hline $1.5-2 \mathrm{~kg}$ & 14 & $32 \%$ \\
$>2-<2.5 \mathrm{~kg}$ & 30 & $68 \%$ \\
\hline
\end{tabular}

Table-VI

Distribution of term neonates as per birth weight $(n=56)$

\begin{tabular}{lcc}
\hline Birth weight & $\begin{array}{c}\text { No. of the } \\
\text { respondents }\end{array}$ & Percentage \\
\hline $2.5-3.5 \mathrm{~kg}$ & 40 & $71 \%$ \\
$>3.5-4 \mathrm{~kg}$ & 16 & $29 \%$ \\
\hline
\end{tabular}

$12 \%$ mother had premature rupture membrane, $12 \%$ had APH, $8 \%$ pre-eclamptic toxemia and hypertension, $6 \%$ had Diabetes mellitus and $4 \%$ had oligohydramnios during pregnancy (Table VII) 
Table-VII

Perinatal risk factors for asphyxia of newborns $(n=100)$

\begin{tabular}{lcc}
\hline Risk factors & Number & Percentage \\
\hline Premature rupture membrane (PR0M) & 12 & $12 \%$ \\
APH (Antepartum hemorrhage) & 12 & $12 \%$ \\
Pre-eclamptic toxemia (PET) & 8 & $8 \%$ \\
Hypertension & 8 & $8 \%$ \\
Diabetes mellitus & 6 & $6 \%$ \\
Oligohydramnios & 4 & $4 \%$ \\
Normal & 50 & $50 \%$ \\
\hline
\end{tabular}

Out of hundred new born $75 \%$ had respiratory distress, $42 \%$ had convulsion, $40 \%$ had cyanosis, 30\% had apnoeic spell and $12 \%$ had sepsis (Table VIII).

\section{Table-VIII}

Distribution of clinical presentation of the asphyxiated newborns.

\begin{tabular}{lcc}
\hline Clinical features & No. of patient & Percentage \\
\hline Respiratory distress & 75 & $75 \%$ \\
Convulsion & 42 & $42 \%$ \\
Cyanosis & 40 & $40 \%$ \\
Apnoeic spell & 30 & $30 \%$ \\
Sepsis & 12 & $12 \%$ \\
\hline
\end{tabular}

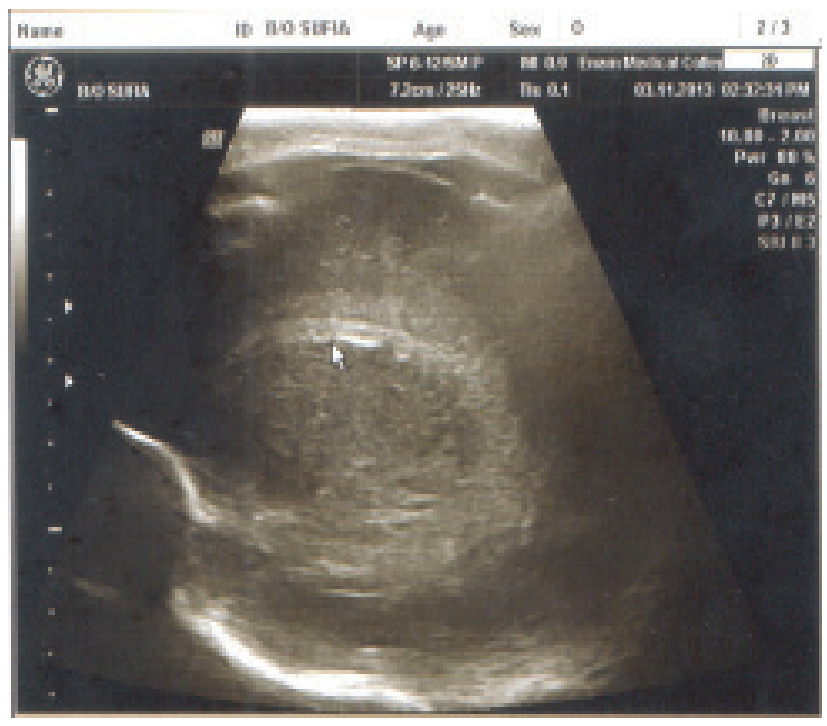

Fig.-1: Periventricular leukomalacia (PVL)
Out of 44 preterm asphyxiated newborn, 13 (29\%) showed periventricular leukomalacia,6 (11\%) germinal matrix haemorrhage, 5 (11\%) IVH, 3 (7\%) showed cerebral oedema and 17 (39\%) showed normal findings (Table IX).

\section{Table-IX}

USG findings in Preterm $(n=44)$

\begin{tabular}{lcc}
\hline Cranial USG finding & No of patient & Percentage \\
\hline Periventricular leukomalacia & 13 & $29 \%$ \\
Germinal matrix hemorrhage & 6 & $14 \%$ \\
IVH(intraventricular hemorrhage) & 5 & $11 \%$ \\
Cerebral oedema & 3 & $7 \%$ \\
Normal finding & 17 & $39 \%$ \\
\hline
\end{tabular}

In 56 term asphyxiated newborn, 24 (43\%) showed cerebral oedema, 3 (5\%) showed intracerebral hemorrhage, 2 (4\%) showed Focal cerebral infarct, $1(2 \%)$ showed IVH, and $26(46 \%)$ showed normal findings (Table X).

\section{Table-X}

USG findings in Term babies $(n=56)$

\begin{tabular}{lcc}
\hline Cranial USG finding & No. of patient & Percentage \\
\hline Cerebral oedema & 24 & $43 \%$ \\
Intracerebral hemorrhage & 3 & $5 \%$ \\
Focal cerebral infarct & 2 & $4 \%$ \\
IVH(intraventricular hemorrhage) & 1 & $2 \%$ \\
Normal finding & 26 & $46 \%$ \\
\hline
\end{tabular}

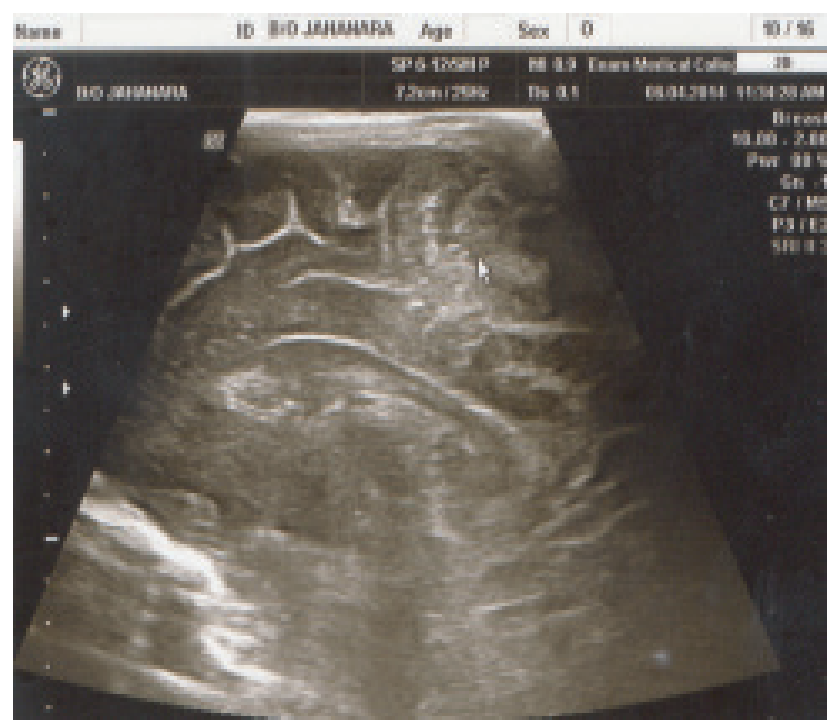

Fig.-2: Periventricular leukomalacia (PVL) 


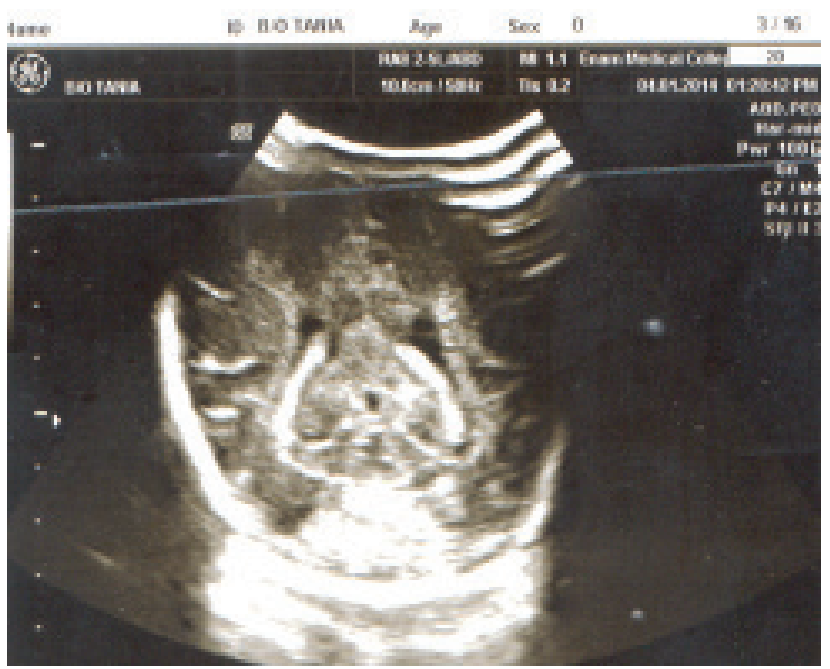

Fig.-3: Intraventricular hemorrhage (IVH)

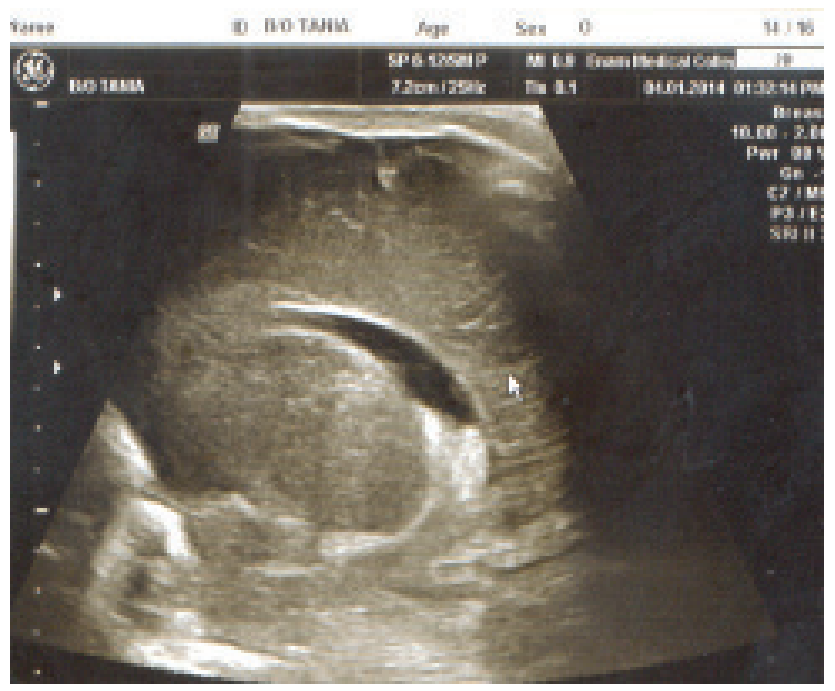

Fig.-5: Cerebral oedema and IVH

\section{Discussion:}

Although there is great improvement in perinatal practice, the mortality and incidence of cerebral palsy caused by asphyxia have remained unchanged partly because of the absence of early diagnosis and identification methods. Due to wide availability of ultrasound machines and other advantages like, it is cheap, easy to perform, non-invasive and can be initiated at a very early stage, even immediately after birth,ultrasound has been used extensively in neonates to evaluate neonatal brain in perinatal asphyxia. This study explores early diagnostic value of cranial sonogram to identify abnormalities in perinatal asphyxia.

In our study there were $52 \%$ female and $48 \%$ male out of one hundred newborn of which 44 were preterm and 56 were term. Most of the studies also showed that birth asphyxia is more common in full term rather than preterm babies. ${ }^{9,10}$ This study shows that majority $(68 \%)$ of the preterm babies were more than

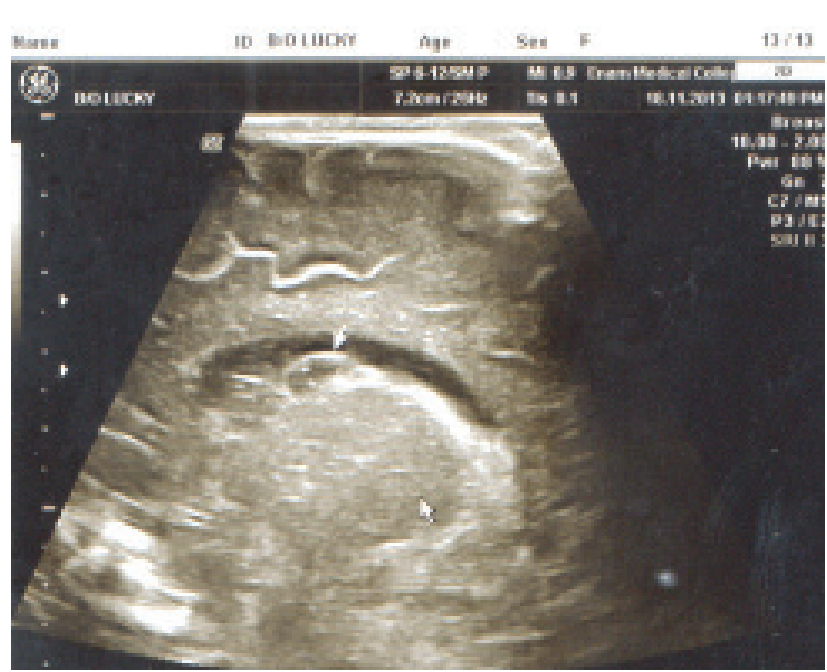

Fig.-4: Germinal matrix hemorrhage

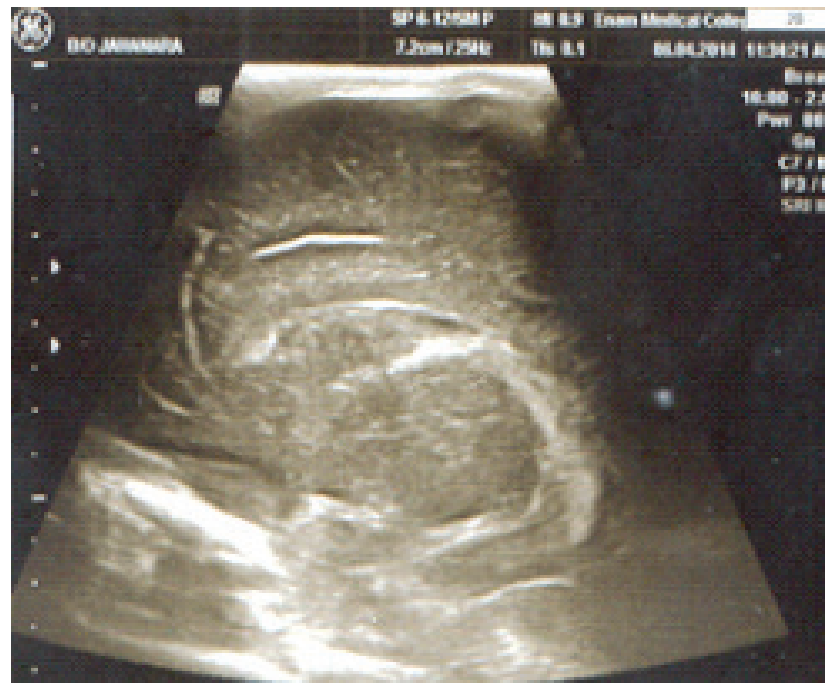

Fig.-6: Cerebral oedema

$2 \mathrm{~kg}$ to less than $2.5 \mathrm{~kg}$ weight group and majority (71\%) of the term babies were of 2.5 to $3.5 \mathrm{~kg}$ weight group. This figures correlate well with the studies of Barr and Dipietro et al. ${ }^{11,12}$

In our study common clinical presentations were $75 \%$ respiratory distress, $42 \%$ convulsion, $40 \%$ cyanosis, $30(30 \%)$ apnoeic spell and $12 \%$ sepsis which were near consistent with other studies. ${ }^{11,13,14,15}$ Respiratory distress was the most common findings $(75 \%)$ in this study. Martin et al found respiratory distress in $48.4 \%$ cases in his study. ${ }^{14}$ Convulsion is also an important presentation in this study, about $42 \%$. Result of Finer et $\mathrm{al}^{16}$ and Goldberg et $\mathrm{al}^{10}$ are near consistent with this study. Cyanosis in this study was found in $40 \%$ cases which is also consistent with other study. ${ }^{13,14}$

Perinatal risk factors were $12 \%$ premature rupture membrane, $12 \%$ APH, $8 \%$ pre-eclamptic toxemia and hypertension, 6 $\%$ Diabetes mellitus and $4 \%$ oligohydramnios. Other studies were also consistent with the present study. ${ }^{14,17}$ 
In preterm asphyxiated baby common sonographic finding is periventricular leukomalacia(PVL) which appear on ultrasound as increased echogenicity in perventricular region. In preterm neonate perventricular region is watershed zone and relatively hypovascular that's play a role in development of PVL. But with maturity of infant watershed zone shifts from periventricular region to a more peripheral location and PVL is less common and cranial ultrasound most commonly shows pattern of diffuse cerebral oedema in term neonate seen as diffuse increased echogenicity of brain with obliterated CSF spaces. In preterm neonate highly vascular germinal matrix is the site of hemorrhage, intraventricular hemorrhage (IVH) may also occur either from rupture of germinal matrix hemorrhage $(\mathrm{GMH})$ or from choroid plexus bleeding. In term neonate germinal matrix is involutes so hemorrhage is uncommon here but intraventricular hemorrhage has been reported from choroid plexus.

In our study common cranial ultrasound findings in preterm asphyxiated neonates were periventricular leukomalacia in $29 \%$ (13) cases, germinal matrix haemorrhage in 14\% (6) cases, IVH in $11 \%$ (5) cases. Other studies ${ }^{18,19}$ also showed that in the preterm, the major lesions are germinal matrix hemorrhage $(\mathrm{GMH})$ or intraventricular hemorrhage (IVH) and periventricular leucomalacia (PVL). USG fared well in the diagnosis of GMH/IVH and PVL. ${ }^{20,21}$ In this study common cranial ultrasound findings of term asphyxiated neonates were cerebral oedema in 43\% (24), intracerebral hemorrhage in $5 \%$ (3)cases. This result also correlate well with other study. ${ }^{22,23}$

\section{Conclusion:}

This study found that cranial USG is a reliable technique for demonstrating the most frequently occurring forms of cerebral injury in perinatal asphyxia, assessing the evolution of the lesion, and following brain development. Our study reveals that PVL, germinal matrix hemorrhage and IVH are common sonogrphic findings in preterm neonates and that of term neonates is cerebral oedema. As cranial sonography is an noninvasive diagnostic technique, simultaneously efficient, effective and safe modality, it can be used as a valuable diagnostic tool and predictor of outcome of hypoxic ischemic brain injury.

\section{Conflict of Interest : None}

\section{References:}

1. Islam MN. Situation of Neonatal Health in Bangladesh. The Orion Medical Journal 2000;6:3-6.

2. Khan MR, Rahman ME. Essence of pediatrics, 3rd ed. Dhaka Bangladesh 2004:21-29.

3. Syke GS, Molloy PM, Johnson, Trnbull A. Fetal distress and condition of newborn infants. BMJ 1993; 287:943-945.

4. Snell RS. Development of nervous system. In: Rob Anthony editors; Clinical Neuroanatomy for Medical Students 5th ed. Philadelphia: Lipincott William \& Wilkins 2001:499-518.
5. Volpe JJ. Neurobiology of periventraicular leukomalacia in the premature infant. Pediatr Res 2001;50:553.

6. Brown JK, Purvis RJ, Forfas JO, Cockburn F. Neurological aspects of perinatal asphyxia. Developrnental Medicine and Child Neurology, 1999;6: 495-502.

7. Gerda van Wezel-Meijler. Cranial Ultrasonography: Advantages and Aims Part 1, Neonatal Cranial Ultrasonography, $1^{\text {st }}$ edn. Berlin: Springer, 2007:3-4.

8. Bracci R, Perrone SN, Buonocore G. The Timing of Neonatal Brain Damage. Biol Neonate 2006;90:145-155.

9. Leven MI. Measurement of the lateral ventricles in preterm infant with real-time ultrasound. Arch Dis Child 2001; 56: 900-904.

10. Goldberg RN et al. Hyperammonaemia associated with perinatal asphyxia. Pediatrics, 2009;64(3):33 6-341.

11. Barr LL. Neonatal cranial ultra sound. Rad Clin N Am, 1999;37(6):1127 -1146.

12. Dipietro MA, Faix RG, Donn SM. Procedural hazards of neonatal ultrasonography. J Clin Ultrasound, 2006;14:361-366.

13. Thomson GD, Teele RL. High frequency linear array transducer for neonatal cerebral sonography. AJR 2001;176: 995- 1001.

14. Martin DJ, Danemans A, Fitz CR. Focal ischemic cerebral injury in the newborn diagnosis by ultrasound and correlation with CT Scan, Pediatr 2003;71:790-793.

15. D Souza SW, Nolan M, Taylor IG. Hearing, speech and language in survivors of severe perinatal asphyxia. Arch Dis Child, 2001;56:245-252.

16. Finer NN, Robertson CM, Richards RT. Hypoxic ischemic encephalopathy in term neonate: Perinatal factor and outcome. J Pediatr 2001;98:112-117.

17. Chowdhury Y Gulati P,Aroras Thirupuram S: Cranial sonography in preterm infants. Indian Pediatrics 2002;29:411-415.

18. Laura RM, Keller SM: Intraventricular Hemorrhage of preterm neonate in Kenneth FS, Stephan A: Pediatric Neurology, ed 3. Mosby, 1999;1:205-219.

19. Patrizia V, Anna L, Valentina D, Francesca A, Giuseppe P, John CP, et al.: Intraventricular hemorrhage and periventricular leucomalacia Imaging in Neonatal Intracranial Ischemia IA Khan, et al. in preterm infants. Obstet Gynecol 2004;104:225-231.

20. Blankenberg FG, Loh NN, Bracci P, D’Arceuil HE, Rhine WD, Norbash AM, et al.: Sonography, CT and MR imaging: a prospective comparison of neonates with suspected intracranial ischemia and hemorrhage. AJNR Am J Neuroradiol 2000;21: 213-218.

21. Blankenberg FG, Norbash AM, Lane B, Stevenson DK, Bracci PM, Enzmann DR: Neonatal intracranial ischemia and hemorrhage: diagnosis with US, CT and MR imaging. Radiology 1996;199:253-259.

22. Alan H, Volpe JJ: Hypoxic ischemic cerebral Injury in the Newborn in Kenneth FS, Stephan A (eds): Pediatr Neurol, ed 3. Mosby 1999;1:191-204.

23. Gupta AK: Hypoxic-Ischemic Encephalopathy in Berry M, Suri S, and Chouwdhry V, JP Brothers (eds): Diagnostic Radiology: Pediatric Radiology. 1997:260-273. 